Note

\title{
Effect of Lactobacillus acidophilus on Iron Bioavailability in Rats
}

\author{
Taishi ODA, Yukio KADO-OKA, and Honoo HASHIBA \\ Technical Research Institute, Snow Brand Milk Products Co. Ltd., \\ Kawagoe 350-11, Japan \\ (Received May 6, 1994)
}

\begin{abstract}
Summary The effect of Lactobacillus acidophilus on iron bioavailability in rats was examined by the hemoglobin regeneration method. For hemoglobin depletion, female Wistar rats were fed an iron-deficient diet at 3 weeks of age for 13 days. Rats were then assigned to one of four groups, such that average blood hemoglobin value and average body weight were similar among the groups. For hemoglobin regeneration, they were fed one of two ferrous sulfate-supplemented diets that contained the following iron levels $(\mathrm{mg} / \mathrm{kg})$ : 13.7 for two groups; 21.7 for the other two groups. In the two groups fed the same diet, one group additionally received oral administration of $2 \mathrm{ml}$ of skim milk fortified with $0.3 \%$ yeast extract once or twice a day for 7 days, and other rats were administered with skim milk fermented by L. acidophilus SBT 2062 in the same manner. Hemoglobin regeneration efficiency (HRE) was significantly higher in the fermented product-given rats than in the skim milk-supplied rats. There was no significant interaction in HRE between the dietary iron group and the oral administration group. These results indicate that L. acidophilus SBT 2062 is effective for increasing of iron bioavailability in rats.
\end{abstract}

Key Words Lactobacillus acidophilus, iron bioavailability, hemoglobin regeneration efficiency, anemia, rats

Milk and its fermented products are important sources of essential minerals, but the iron content of dairy products is low (1).

Schaafsma et al. (2) reported that yogurt, a culture of Lactobacillus delbrueckii subsp. bulgaricus and Streptococcus salivarius subsp. thermophilus, lowered intestinal iron absorption in rats fed ferrous sulfate as compared to milk consumed, which resulted in lowered blood hemoglobin value. These phenomena were confirmed in another study (3). Vonk et al. (4) found a significant relationship between intestinal transit time and iron absorption in rats fed milk and yogurt. However, there was no report on iron bioavailability modified with lactic acid bacteria except $L$. delbrueckii subsp. bulgaricus and $S$. salivarius subsp. thermophilus.

The purpose of this study was to determine the effect of $L$. acidophilus on iron 
bioavailability in rats by the hemoglobin regeneration method (5).

Materials and methods. 1) Samples: Skim milk powder was obtained from Snow Brand Milk Products Co. (Kawagoe, Japan). An 11\% reconstituted skim milk medium fortified with $0.3 \%$ yeast extract (Difco Laboratory, Detroit, MI, U.S.A.) was heat-treated at $115^{\circ} \mathrm{C}$ for $20 \mathrm{~min}$. L. acidophilus SBT 2062 was inoculated at $3 \%$ into the medium, and incubated at $37^{\circ} \mathrm{C}$ for $16 \mathrm{~h}$. The final $\mathrm{pH}$ was 3.8.

2) Analyses: The blood hemoglobin value was determined by the colorimetric method with Hemoglobin B Test Wako (Wako Pure Chemical Industries, Tokyo, Japan). Diets, skim milk medium, and fermented product were decomposed as previously reported (6). The iron concentration in each sample was determined by atomic emission spectrometry.

3) Animals and diets: Twenty-four female Wistar rats at 3 weeks of age were purchased from Charles River Japan Inc. (Ibaraki, Japan), and were housed in individual stainless steel, wire mesh-bottom cages in a 12-h light/dark cycle (lights on at $08: 00$ ). Purified diet and deionized water were provided ad libitum. For hemoglobin depletion, they were fed an iron-deficient diet that contained 4.7 $\mathrm{mg} / \mathrm{kg}$ of iron for 13 days. The iron-deficient diet included the following $(\mathrm{g} / 100 \mathrm{~g}$ diet): casein, 20; corn oil, 5; corn starch, 65; cellulose (filter paper powder type D, Toyo Filter Paper Co., Tokyo, Japan), 5; AIN-76 mineral mixture that omitted ferric citrate (Oriental Yeast Co., Tokyo, Japan), 3.5; AIN-76 vitamin mixture (Oriental Yeast Co.), 1; DL-methionine, 0.3; choline chloride, 0.2. After the depletion period, blood was withdrawn from the tail vein, and collected for analysis of initial hemoglobin value. Initial body weight was measured. Rats were then assigned to one of four groups ( $n=6 /$ group), such that the average initial hemoglobin value and average initial body weight were similar among the groups, respectively. For hemoglobin regeneration, they were fed one of two ferrous sulfatesupplemented diets that contained the following iron level $(\mathrm{mg} / \mathrm{kg}): 13.7$ for two groups; 21.7 for other two groups. Ferrous sulfate-supplemented diets included the following (g/100 g diet): casein, 20; corn oil, 5; corn starch, 65; cellulose, 5; AIN76 mineral mixture modified with replacing $6.0 \mathrm{~g} / \mathrm{kg}$ of ferric citrate by either 1.42 or $2.84 \mathrm{~g} / \mathrm{kg}$ of ferrous sulfate heptahydrate (Oriental Yeast Co.), 3.5; AIN-76 vitamin mixture, 1; DL-methionine, 0.3; choline chloride, 0.2. Among the two groups of rats fed the same diet, one group additionally received oral administration of $2 \mathrm{ml}$ of skim milk medium in once or twice a day at 10:00-11:00 and/or 16:00$17: 00$ for 7 days, and other rats were administered with fermented product in the same manner. After the regeneration period, blood was withdrawn from the tail vein, and collected for analysis of the final hemoglobin value. The final body weight was measured. Iron intake was calculated from food intake and dietary iron concentration, and from total amount of oral administration of each sample and its iron concentration. Hemoglobin regeneration efficiency (HRE) was calculated from the initial and final hemoglobin values, the initial and final body weights, and the iron intake, according to Zhang et al. (5). 
Statistical analysis was made by two-factor analysis of variance (ANOVA) (7). Linear regression analysis was performed on the some of the data, and correlation coefficient was determined (7). HRE was also analyzed by two-factor analysis of covariance with either body weight gain or food efficiency (7), because there was a significant relationship between HRE and either body weight gain or food efficiency.

Results and discussion. The effect of L. acidophilus SBT 2062 on iron bioavailability in rats is shown in Table 1 . The final hemoglobin value or iron intake was not different between the skim milk group and the fermented product group, but HRE was significantly higher in the fermented product group than in the skim milk group. There was no significant interaction of dietary iron level and oral administration group on HRE. Food intake was similar between the test substance groups (Table 2). Body weight gain or food efficiency was higher in the fermented product group than in the skim milk group. A slight but significant relationship between HRE and either body weight gain $(n=24, r=0.46, p<0.02)$ or food efficiency $(n=24, r=0.52, p<0.01)$ was observed. No relationship between HRE and food intake was observed (data not shown). Analysis of covariance of HRE with either body weight gain or food efficiency revealed that HRE was also significantly higher in the fermented product group than in the skim milk group $(p<0.05)$. Therefore, HRE was not attributed to growth parameters. None of the rats exhibited diarrhea. These results indicate that $L$. acidophilus SBT 2062 is effective for increasing the bioavailability of iron in rats. Further studies are needed

Table 1. Initial and final hemoglobin values, iron intake, and hemoglobin regeneration efficiency in rats fed one of two ferrous sulfate-supplemented diets in addition to oral administration of either skim milk fortified with $0.3 \%$ yeast extract or skim milk fermented by Lactobacillus acidophilus SBT $2062 .{ }^{1}$

\begin{tabular}{cccccc}
\hline $\begin{array}{c}\text { Dietary iron } \\
(\mathrm{mg} / \mathrm{kg})\end{array}$ & $\begin{array}{c}\text { Test } \\
\text { substance }\end{array}$ & $\begin{array}{c}\text { Initial hemoglobin } \\
(\mathrm{g} / \text { liter })\end{array}$ & $\begin{array}{c}\text { Final hemoglobin } \\
(\mathrm{g} / \text { liter })\end{array}$ & $\begin{array}{c}\text { Iron intake } \\
(\mu \mathrm{g} / \mathrm{day})\end{array}$ & $\begin{array}{c}\text { HRE }^{4} \\
(\%)\end{array}$ \\
\hline 13.7 & $\mathrm{SM}$ & $77 \pm 9$ & $93 \pm 9$ & $186 \pm 6$ & $73 \pm 5$ \\
13.7 & $\mathrm{SMF}$ & $78 \pm 8$ & $98 \pm 9$ & $188 \pm 17$ & $84 \pm 9$ \\
21.7 & $\mathrm{SM}$ & $78 \pm 8$ & $118 \pm 8$ & $316 \pm 35$ & $80 \pm 6$ \\
21.7 & $\mathrm{SMF}$ & $78 \pm 6$ & $124 \pm 8$ & $326 \pm 20$ & $95 \pm 10$ \\
ANOVA table & & & & \\
Iron & $\mathrm{NS}$ & 0.0001 & 0.0001 & 0.01 \\
Substance & $\mathrm{NS}$ & $\mathrm{NS}$ & $\mathrm{NS}$ & 0.0006 \\
Iron $\times$ substance & $\mathrm{NS}$ & $\mathrm{NS}$ & $\mathrm{NS}$ & $\mathrm{NS}$ \\
\hline
\end{tabular}

${ }^{1}$ Each value is mean \pm SD for 6 rats; NS, not significant $(p>0.05) . \quad{ }^{2}$ Rats were orally administered $2 \mathrm{ml}$ of either test substance once or twice a day for 7 days, and were totally administered $22 \mathrm{ml}$ of either material; SM, skim milk fortified with $0.3 \%$ yeast extract; SMF, skim milk fermented by $L$. acidophilus SBT $2062 .{ }^{3}$ This value at the range from 65 to $88 \mathrm{~g} /$ liter was induced by feeding rats on the iron-deficient diet that contained $4.7 \mathrm{mg} / \mathrm{kg}$ of iron at 3 weeks of age for 13 days. ${ }^{4}$ Hemoglobin regeneration efficiency. Calculated according to Zhang et al. (5). 
Table 2. Body weight, food intake, and food efficiency in rats fed one of two ferrous sulfate-supplemented diets in addition to oral administration of either skim milk fortified with $0.3 \%$ yeast extract or skim milk fermented by Lactobacillus acidophilus SBT 2062. ${ }^{1}$

\begin{tabular}{cccccc}
\hline $\begin{array}{c}\text { Dietary iron } \\
(\mathrm{mg} / \mathrm{kg})\end{array}$ & $\begin{array}{c}\text { Test } \\
\text { substance }\end{array}$ & $\begin{array}{c}\text { Body weight } \\
(\mathrm{g})\end{array}$ & $\begin{array}{c}\text { Weight gain } \\
(\mathrm{g} / \text { day })\end{array}$ & $\begin{array}{c}\text { Food intake } \\
(\mathrm{g} / \text { day })\end{array}$ & $\begin{array}{c}\text { Food } \\
\text { efficiency }^{4}(\%)\end{array}$ \\
\hline 13.7 & SM & $146 \pm 6$ & $3.3 \pm 0.3$ & $13.6 \pm 0.5$ & $24 \pm 2$ \\
13.7 & SMF & $148 \pm 9$ & $3.6 \pm 0.3$ & $13.8 \pm 1.2$ & $26 \pm 2$ \\
21.7 & SM & $149 \pm 9$ & $3.6 \pm 0.8$ & $14.6 \pm 1.6$ & $25 \pm 4$ \\
21.7 & SMF & $155 \pm 10$ & $4.6 \pm 0.5$ & $15.0 \pm 0.9$ & $30 \pm 3$ \\
ANOVA table & & NS & 0.007 & 0.03 & NS \\
Iron & & NS & 0.01 & NS & 0.007 \\
Substance & NS & NS & NS & NS \\
Iron $\times$ substance & & &
\end{tabular}

${ }^{1,2}$ See Table $1 .{ }^{3}$ Final body weight. Mean initial body weight was $123 \mathrm{~g}$. ${ }^{4}$ Weight gain/food intake $\times 100$.

to elucidate the active component that increases iron availability in rats, and to clarify the relationship between HRE and intestinal transit time, intestinal iron absorption, or hemoglobin synthesis in rats given skim milk or skim milk fermented by $L$. acidophilus SBT 2062.

\section{REFERENCES}

1) Jackson, L. S., and Lee, K. (1992): The effect of dairy products on iron availability. Crit. Rev. Food Sci. Nutr., 31, 259-270.

2) Schaafsma, G., Dekker, P. R., and de Waard, H. (1988): Nutritional aspects of yogurt. 2. Bioavailability of essential minerals and trace elements. Neth. Milk Dairy J., 42, 135-146.

3) Gruden, N., and Matausic, S. (1989): The effect of yogurt upon iron metabolism in young rats. Spec. Publ. R. Soc. Chem., 72, 176-178.

4) Vonk, A. D., Schaafsma, G., Dekker, P. R., and de Waard, H. (1988): Relationship between intestinal transit time and iron absorption from milk and yogurt in rats. Neth. Milk Dairy J., 42, 147-154.

5) Zhang, D., Hendricks, D. G., and Mahoney, A. W. (1989): Bioavailability of total iron from meat, spinach (Spinacea oleracea L.) and meat-spinach mixtures by anaemic and non-anaemic rats. Br. J. Nutr., 61, 331-343.

6) Analytical Methods Committee (1960): Methods for the destruction of organic matter. Analyst, 85, 643-656.

7) Joyner, S. P. (ed.) (1985): SAS/STAT ${ }^{\mathrm{TM}}$ Guide for Personal Computers, 6th Ed., SAS Institute, Cary, NC, U.S.A. 